\title{
UTILIZATION OF VOLUME COMPOSITE FRACTION IN KEPOK BANANA STEM (MASSA PARADISIACA) RANDOM CORNER ORIENTATION WITH POLYESTER MATRIX AGAINST THE MECHANICAL CHARACTERISTIC
}

\author{
Basuki Widodo ${ }^{1 *}$, Anang Subardi² \\ ${ }^{1,2}$ Mechanical Engineering, Industrial Technology Faculty National Institute of Technology, \\ Malang, Indonesia
}

*Corresponding Email: basuki42@yahoo.com

\begin{abstract}
This study aims to determine the effect of volume fraction $(10 \%, 20 \%, 30 \%, 40 \%, 50 \%)$ of composite banana stem fiber with polyester matrix on tensile strength and impact strength. From the results of the study obtained an average strength value the most optimal tensile is found in the $10 \%$ fiber volume fraction and $90 \%$ matrix that is $51.863 \mathrm{~N} / \mathrm{mm}^{2}$ and strain value $5.754 \mathrm{~N} / \mathrm{mm}^{2}$. As for the lowest tensile strength at $20 \%$ fiber volume fraction and $80 \%$ matrix that is $36.356 \mathrm{~N} / \mathrm{mm}^{2}$ and strain value $7.796 \%$. The composite which has the highest average energy and impact value is the $50 \%$ volume fraction matrix $50 \%$ has an absorption rate with an average absorbed energy value of 0.8093 Joules and an average Impact Price of 0.0101 Joules / $\mathrm{mm} 2$, while the lowest is the volume fraction of $20 \%, 80 \%$ matrix with an average energy value of 0.4129 Joules and an average Impact Price of $0.0052 \mathrm{Joules} / \mathrm{mm}^{2}$. It can be concluded that the addition of fiber volume fraction affects the tensile strength and impact strength.
\end{abstract}

Keywords: Tensile strength, impact strength, polyester resin, banana stem fiber.

\section{Introduction}

The development of science and technology continues to develop in all fields, such as the field of vehicle construction, construction of buildings, industry, and in the field of material engineering, especially composites. This development is inseparable from the increasing needs and scarcity of materials available in nature. The use of material for industry still relies heavily on nonrenewable mining materials. Therefore, we need a replacement material that can be renewed, and has mechanical properties that can offset the superiority of mining materials.

Composite material is a material that combines the properties of two or more materials to form a new material that has the superiority of each material.

The use of composite materials as a substitute for metals in the field of engineering has become increasingly widespread, not only in the field of transportation but also in other fields such as property, architecture and so on. Various benefits of the use of composites are increasingly felt by industry and society, for example lightweight, corrosion resistant, waterproof, attractive performance, and without machining processes. Due to the lightweight nature of the composite panel, the burden due to the construction also becomes lighter. The price of component products made from composites can go down (cost reduction) by up to $60 \%$ compared to metal products.

At present many new natural resources are being developed in the field of composites, one of them is banana (Musa paradisiaca). The use of bananas is currently only fixated on the fruit while the banana stems are underutilized and become waste. So, it is necessary to use and research to develop banana stems as an alternative material for making composites.

\section{Composite}

Composites are materials that are formed when two or more different components are combined [1]. P. Kumar Mehta in his book Structure, Properties, and Materials [1] explains that Composite is a material that is formed from a combination of two or more materials, where the mechanical properties of the forming material are different. Because the different forming characteristics, a new material will be produced, namely composites that have different mechanical and characteristic properties from the forming materials. 


\subsection{Composite Components}

\subsubsection{Matrix}

The matrix in the composite structure can come from polymeric materials, metals, or ceramics. The matrix generally functions to bind fibers into one composite structure [2].

\subsubsection{Filler}

Filler is a material used in making composites, usually in the form of fiber or powder. Fibers that are often used in making composites include EGlass, Boron, Carbon fibers and so on. Can also use natural fibers such as kenaf, banana, jute, hemp, cantula and others.

\subsection{Fiber Orientation in Composites}

Composite sheet is a material composed of layers - bound to one another. Each layer consists of many fibers submerged in the matrix. As well as length (continuous fiber) is used to make the layer, the fiber can be oriented in one direction (unidirectional orientation) or in two directions (bidirectional orientation). This layer can also be constructed using short fibers (discontinuous fiber) both in one direction and randomly. Some layers are stacked with each other to get a certain thickness will form a sheet (laminate), where the variation of layers in the sheet consists of fibers in one direction or different directions.

\subsubsection{Fiber}

Fiber is an object whose diameter is very large in proportion to its length. Basically, textile fibers come from three main elements, namely fibers originating from nature (plants and animals), artificial fibers (synthetic) and minerals (asbestos, metals).

- Natural fibers derived from plants, among others: cotton, linen, rayon, pineapple, bananas. Natural fibers derived from animals, namely: from beriberi feathers, while the material derived from these fibers is wool, while fibers from silkworms produce silk textile materials.

- Artificial fibers (thermoplastics) textile materials derived from artificial fibers in the form of Dacron, polyester, nylon.

- Excavated fibers are fibers whose basic ingredients come from minerals such as asbestos, metals, metal threads. Examples of asbestos, metal and metal thread. Metal fiber is more widely used to make various types of threads such as gold thread, silver thread, copper, aluminum, besides that there is also a thread coated with plastic.

\subsubsection{Resin}

Resin is a material in the form of liquid at room temperature, or solid material that can melt at temperatures above $2000^{\circ} \mathrm{C}$. Basically, the resin is a matrix, so it has the same function as the matrix.

Polyester resins have low prices, are easy to use and versatility. In addition, polyester resins have impact resistance, weather resistance, transparency and good surface effects. The disadvantage of using polyester resin is that it has poor adhesion and inhibitory properties of air and fillers. The hardener type in the curing system for polyether resins is mostly peroxide such as benzoyl peroxide or Methyl-Ethyl Ketone Peroxide, better known as MEKPO. While the filler that is widely used is calcium carbonate because of its cheap price and high ability in strength against the pressure.

\subsection{Support and Research Results}

Based on the shape of the amplifier, the composite outline is broadly classified into three types [3], namely: particle composites, fiber composites and layers composites.

a. Particulate composites

It is a composite that uses powder particles as reinforcement and is evenly distributed in the matrix.

b. Fibrous composites

Fibrous composites are composites consisting of fibers and matrices.

Types of fiber composites are divided into 4 types, namely:

- Continuous fiber composite (composite reinforced by continuous fiber).

- Woven fiber composite (composite reinforced by woven fiber).

- Chopped fiber composite (composite reinforced by short / random fibers)

- Hybrid composite (composite reinforced by continuous fiber and random fiber).

c. Laminates composites

This composite type consists of two or more layers which are combined into one and each layer has its own characteristics. Based on the type of matrix used composite can be divided into 3 groups, namely:

- Metal matrix composites / MMC

- Ceramic matrix composites / CMC

- Polymer matrix composites / PMC 
Factors that affect the performance of fiber composites include:

\section{Fiber Factor}

Fiber is a matrix filling material used to improve the properties and structure of matrices that it does not have, it is also expected to be able to become a matrix reinforcement material for composites to withstand the forces that occur.

2. Location of Fiber

In making composite the layout and direction in the matrix will determine the mechanical strength of the composite, where the location and direction can affect the performance of the composite.

3. Fiber Length

The length of the fiber in making the fiber composite on the matrix greatly influences the strength. There are two in making long fiber composites and short fibers.

\section{Fiber Form}

The shape of the fiber used for making composites affects the diameter of the fiber.

\section{Matrix Factors}

The matrix in the composite functions as a fiber binding material into a structural unit, protecting from external damage, forwarding or moving external loads on the sliding plane between the fiber and the matrix.

6. Fiber and matrix bonding factors

A good fiber composite must be able to absorb the matrix which makes it easy to occur between two phases [4].

7. Catalyst

Much or little of the catalyst given in the manufacture of composites also affects the mechanical properties produced by the composite later.

8. Void

Void or air bubbles are a result that cannot be avoided during the manufacturing process.

\subsection{Composite Manufacturing Process}

Composite materials can be produced by a variety of manufacturing process methods, these manufacturing methods are adapted to the type of composite matrix and the desired form of composite material according to subsequent applications.

Hand lay-up process is done in cold conditions and by utilizing hand skills. Composite material fibers are arranged in such a way as to form a mold, then pour the resin as a binder between one layer of fiber with another layer. And so on, so that according to the size and shape that has been determined.

\subsection{Banana Stem Fiber}

Banana stem fibers are natural fibers produced from banana tree trunks. According to Rukmana [5] Banana is a pseudo shrub plant (pseudo stem) whose height varies between 1-4 meters, depending on the variety. The leaves are wide, long, the bones of the leaves, and the edges do not have a compact bond, so they are easily torn when exposed to strong winds. The stems have bulbs (bulbs) are very large and there are many eyes that can become bud shoots. The flowers are single, out at the end of the stem and only once flowering throughout his life (manocropic). Table 1 shows the chemical composition of banana fiber.

Table 1 Composition of Natural Fiber Chemical Elements

\begin{tabular}{ll}
\hline Dimension & $\mathrm{mm}$ \\
\hline $\mathrm{W}$ & 19 \\
\hline $\mathrm{G}$ & 50 \\
\hline $\mathrm{D}$ & 115 \\
\hline $\mathrm{LO}$ & 246 \\
\hline $\mathrm{R}$ & 78 \\
\hline $\mathrm{WO}$ & 29 \\
\hline $\mathrm{L}$ & 57 \\
\hline $\mathrm{T}$ & 3.2 \\
\hline
\end{tabular}

\subsection{Composite Tensile Strength}

Tensile testing aims to determine the maximum stress, yield stress, and strain (extension). Tensile loading is done by giving the load slowly until the composite material has broken.

For specimens selected in this tensile test use specimens with dimensions in table ASTM D 638-3 type III in rectangular shape.

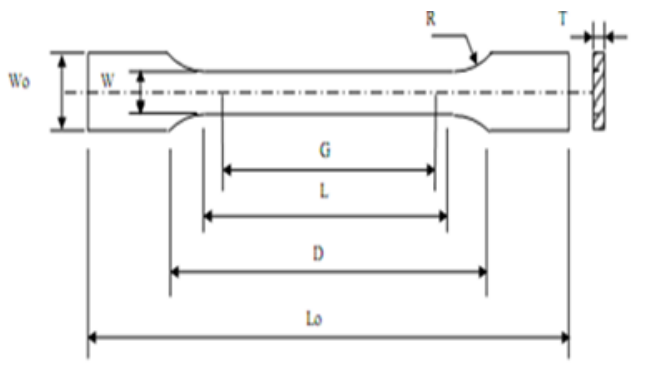

Figure 1 Dimension of ASTM Tensile Test Specimen D638 - 3 


\subsection{Relationship of Fiber and Matrix Weight Fractions on Composites}

1. Volume Faction

The volume fraction is the ratio of the number of fibers and the matrix in the composite.

Fiber volume fraction $: V_{f}=\frac{V_{f}}{V_{c}}$

Matrix volume fraction: $V_{m}=\frac{V_{m}}{V_{c}}$

where:

$V_{f} \quad$ : fiber volume

$V_{m}$ : matrix volume

$V_{c} \quad$ : composite volume

2. Weight Faction

Fiber weight fraction $: W_{f}=\frac{W_{f}}{W_{c}}$
Matrix weight fraction : $W_{m}=\frac{W_{m}}{W_{c}}$

where:

$W_{f}$ : fiber weight

$W_{m}$ : matrix weight

$W_{c}$ : composite weight

\section{Analysis and Discussion}

In the Research Process, the test sample is made with five variations of the volume fraction and each volume fraction is made in triplicate as a comparison. Test samples that have been made in the direction of the orientation of the fiber at random (random) analyzed the differences of each sample to determine its tensile strength.

Table 2 Results of Tensile Test

\begin{tabular}{|c|c|c|c|c|c|}
\hline No & Name of Specimen & $\begin{array}{l}\text { Maximum Tensile } \\
\text { Strength }(\mathrm{N})\end{array}$ & $\begin{array}{l}\text { Max_Disp } \\
(\mathrm{mm})\end{array}$ & $\begin{array}{c}\text { Stress } \\
\left(\mathrm{N} / \mathrm{mm}^{2}\right)\end{array}$ & Strain $(\%)$ \\
\hline 1 & \multirow{3}{*}{$\begin{array}{c}\text { Banana Fiber } \\
10 \% \text { - } 90 \% \text { Matrix }\end{array}$} & $3,217.68$ & 5.3 & 52.96 & 13.76 \\
\hline 2 & & $3,021.48$ & 5.0 & 49.63 & 10.02 \\
\hline \multirow[t]{2}{*}{3} & & $3,217.68$ & 5.8 & 53.00 & 11.66 \\
\hline & average & $3,152.28$ & 5.37 & 51.86 & 11.81 \\
\hline 1 & \multirow{3}{*}{$\begin{array}{c}\text { Banana Fiber } \\
\text { 20\% - 80\% Matrix }\end{array}$} & $1,726.56$ & 2.9 & 28.42 & 5.92 \\
\hline \multirow{3}{*}{$\frac{2}{3}$} & & $2,413.26$ & 4.1 & 39.76 & 8.14 \\
\hline & & $2,481.93$ & 4.7 & 40.89 & 9.33 \\
\hline & average & $2,207.25$ & 3.9 & 36.36 & 7.8 \\
\hline 1 & \multirow{3}{*}{$\begin{array}{c}\text { Banana Fiber } \\
30 \%-70 \% \text { Matrix }\end{array}$} & $2,285.73$ & 3.8 & 37.57 & 7.68 \\
\hline 2 & & $2,481.98$ & 3.7 & 40.78 & 7.38 \\
\hline \multirow[t]{2}{*}{3} & & $2,864.52$ & 4.35 & 47.13 & 8.78 \\
\hline & average & $6,468.75$ & 3.95 & 41.83 & 7.94 \\
\hline 1 & \multirow{3}{*}{$\begin{array}{c}\text { Banana Fiber } \\
40 \% \text { - 60\% Matrix }\end{array}$} & $2,334.78$ & 3.7 & 38.43 & 7.46 \\
\hline 2 & & $3,001.86$ & 4.95 & 49.43 & 9.93 \\
\hline \multirow[t]{2}{*}{3} & & $2,599.65$ & 4.2 & 42.75 & 8.45 \\
\hline & average & $6,468.75$ & 4.28 & 43.53 & 8.61 \\
\hline 1 & \multirow{3}{*}{$\begin{array}{c}\text { Banana Fiber } \\
50 \%-50 \% \text { Matrix }\end{array}$} & $3,149.01$ & 4.9 & 51.87 & 9.89 \\
\hline 2 & & $2,727.18$ & 4.4 & 44.88 & 8.82 \\
\hline \multirow[t]{2}{*}{3} & & $2,197.44$ & 4.0 & 36.20 & 8.04 \\
\hline & average & $2,691.21$ & 4.43 & 44.32 & 8.92 \\
\hline
\end{tabular}




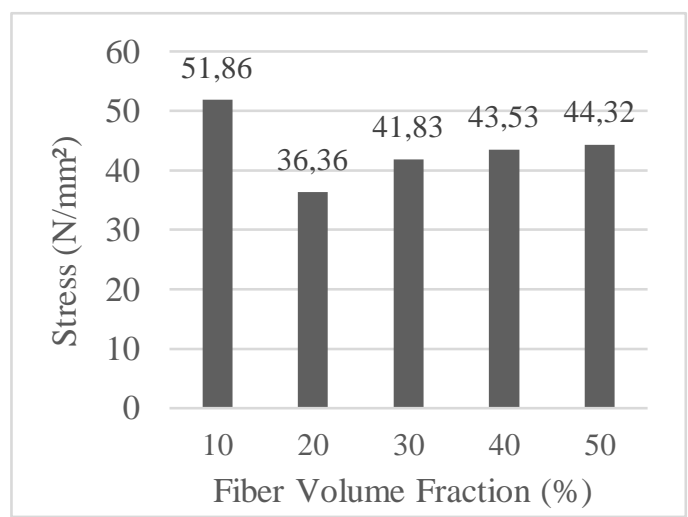

(a)

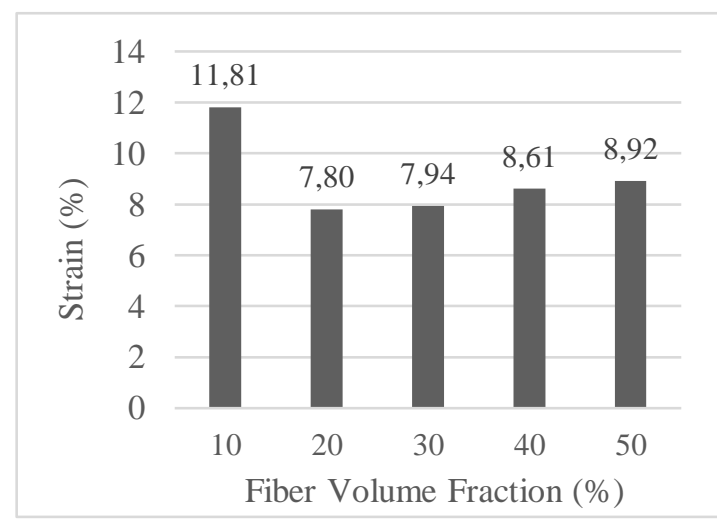

(b)

Figure 2 Comparison between fiber volume fraction and (a) stress; (b) strain

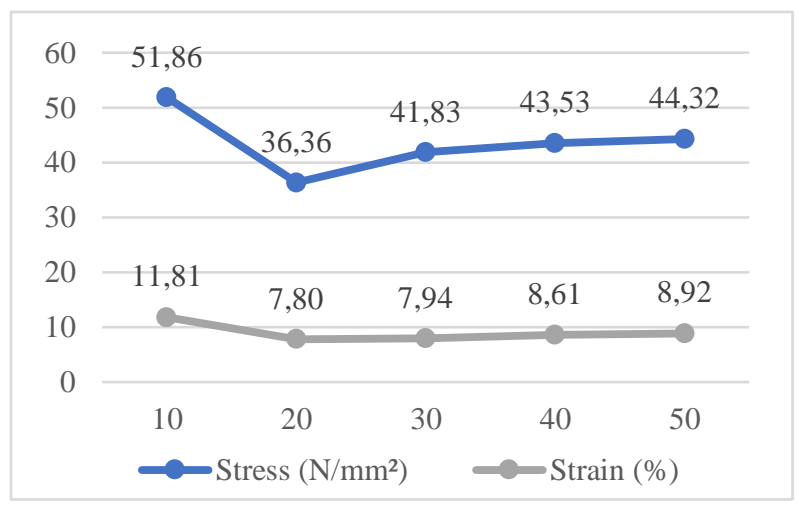

Figure 3 Comparison of stress-strain

\subsection{Analysis and Discussion of Tensile Test Results}

Of the five test samples, namely the volume fraction $(10 \%-90 \%),(20 \%-80 \%),(30 \%-70 \%)$, $(40 \%-60 \%)$ and $(50 \%-50 \%)$. The most optimal tensile strength is found in the $10 \%$ fiber volume fraction - and $90 \%$ matrix that is $51,863 \mathrm{~N} / \mathrm{mm} 2$ and the strain value is $5.754 \%$. While the lowest average tensile strength value in the volume fraction of $20 \%-80 \%$ is $36,356 \mathrm{~N} / \mathrm{mm}^{2}$ with strain $7,796 \%$. Based on the graph data above shows that the increasing percentage of the volume fraction of the fiber affects the tensile strength and strain. It can be seen in graph 4.1 and graph 4.2 where the fiber volume fraction is $20 \%$ and the matrix $80 \%$ which has the lowest tensile strength and strain value compared to other fiber volume fractions. This is because the matrix is too little which results in one fiber with another fiber not being bound properly and apart from that the matrix does not enter completely into the pores of the fiber, so that during the tensile testing the fiber is not able to withstand the forces on the matrix properly. And there are many vacancies that can cause a decrease in the value of the composite tensile strength. This is caused when the composite receives a load, the voltage area will move to the void region, so that the stress concentration occurs in that area. Because the area is not fully filled with fibers and matrices. This is in line with Teuku Rihayat and Suryani [6] which states that the tendency to decrease the value of tensile strength is due to the small amount of fiber in the composite so that the matrix is easily trapped by air bubbles in the composite so that the bond between the fiber and the resin does not occur properly. 
Table 2 Results of Impact Test

\begin{tabular}{|c|c|c|c|c|c|c|}
\hline No & Name of Specimen & $\begin{array}{l}\text { Large } \\
\left(\mathrm{mm}^{2}\right)\end{array}$ & $\begin{array}{c}\text { Starting } \\
\text { Corner }\left(\alpha^{\mathrm{o}}\right)\end{array}$ & $\begin{array}{l}\text { End Corner } \\
\qquad\left(\beta^{\circ}\right)\end{array}$ & $\begin{array}{l}\text { Energy } \\
\text { (Joule) }\end{array}$ & $\begin{array}{c}\text { HI } \\
\left(\text { Joule } / \mathrm{mm}^{2} \text { ) }\right.\end{array}$ \\
\hline 1 & \multirow{3}{*}{$\begin{array}{c}\text { Banana Fiber } \\
10 \%-90 \% \text { Matrix }\end{array}$} & 80 & 45 & 43.5 & 0.3111 & 0.0039 \\
\hline 2 & & 80 & 45 & 43 & 0.4129 & 0.0052 \\
\hline \multirow[t]{2}{*}{3} & & 80 & 45 & 42 & 0.6137 & 0.0077 \\
\hline & average & 80 & 45 & 42.83 & 0.4459 & 0.0056 \\
\hline 1 & \multirow{3}{*}{$\begin{array}{c}\text { Banana Fiber } \\
20 \%-80 \% \text { Matrix }\end{array}$} & 80 & 45 & 43 & 0.4129 & 0.0052 \\
\hline 2 & & 80 & 45 & 43 & 0.4129 & 0.0052 \\
\hline \multirow[t]{2}{*}{3} & & 80 & 45 & 43 & 0.4129 & 0.0052 \\
\hline & average & 80 & 45 & 43 & 0.4129 & 0.0052 \\
\hline 1 & \multirow{3}{*}{$\begin{array}{l}\text { Banana Fiber } \\
30 \%-70 \% \text { Matrix }\end{array}$} & 80 & 45 & 42 & 0.6137 & 0.0077 \\
\hline 2 & & 80 & 45 & 43 & 0.4129 & 0.0052 \\
\hline \multirow[t]{2}{*}{3} & & 80 & 45 & 42 & 0.6137 & 0.0077 \\
\hline & average & 80 & 45 & 42.33 & 0.5467 & 0.0068 \\
\hline 1 & \multirow{3}{*}{$\begin{array}{c}\text { Banana Fiber } \\
40 \%-60 \% \text { Matrix }\end{array}$} & 80 & 45 & 41.5 & 0.7126 & 0.0089 \\
\hline 2 & & 80 & 45 & 41 & 0.8106 & 0.0101 \\
\hline \multirow[t]{2}{*}{3} & & 80 & 45 & 41 & 0.8106 & 0.0101 \\
\hline & average & 80 & 45 & 41.16 & 0.7779 & 0.0097 \\
\hline 1 & \multirow{3}{*}{$\begin{array}{c}\text { Banana Fiber } \\
50 \%-50 \% \text { Matrix }\end{array}$} & 80 & 45 & 41 & 0.8106 & 0.0101 \\
\hline 2 & & 80 & 45 & 42 & 0.6137 & 0.0077 \\
\hline \multirow[t]{2}{*}{3} & & 80 & 45 & 40 & 1.0037 & 0.0125 \\
\hline & average & 80 & 45 & 41 & 0.8093 & 0.0101 \\
\hline
\end{tabular}

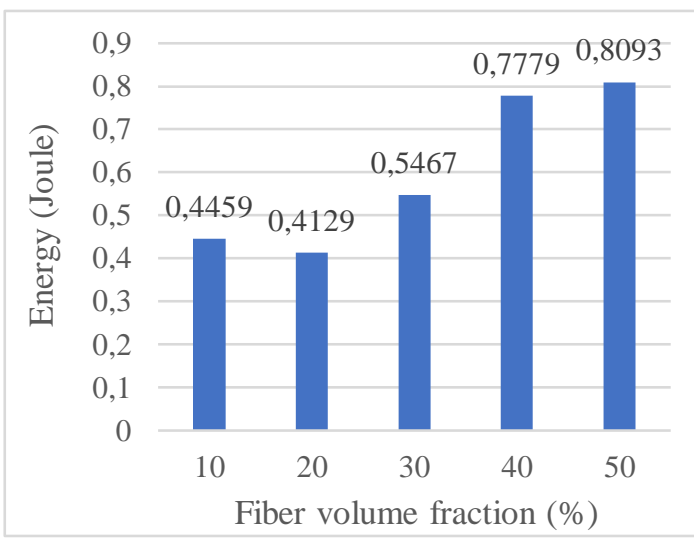

(a)

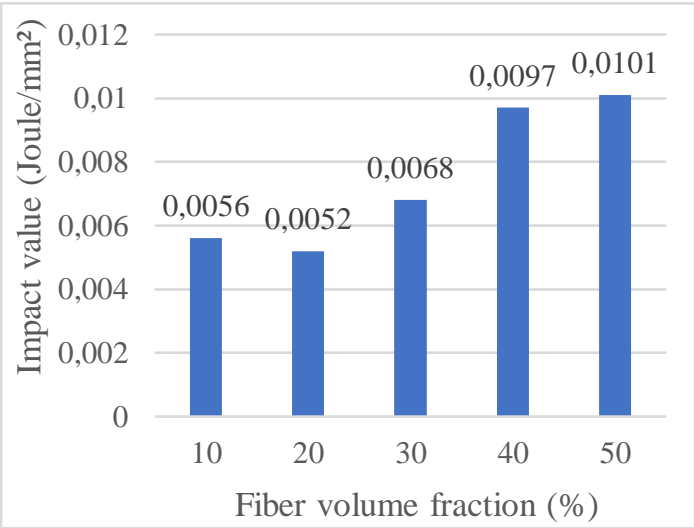

(b)

Figure 4 Comparison between fiber volume fraction and (a) energy; (b) impact value

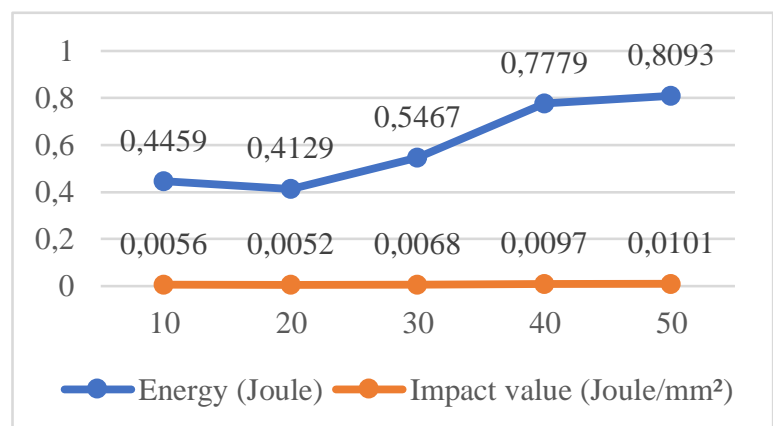

Figure 5 Comparison of energy-impact value 


\subsection{Analysis and Discussion of Impact Test Results}

From the Calculations and graphs of the five impact test samples that have been tested, namely the volume fraction $(10 \%-90 \%),(20 \%-80 \%)$, $(30 \%-70 \%),(40 \%-60 \%)$, and $(50 \%-50 \%)$. In the banana fiber, the smallest energy absorbed is at a volume fraction of $20 \% 80 \%$ matrix with an average energy value of 0.4129 Joules and an average Impact Price of 0.0052 joules $/ \mathrm{mm}^{2}$, lower than the composition of other volume fractions. While the absorption rate of the most optimal value than the others is in the volume fraction of $50 \%-50 \%$ matrix has an absorption rate with an average value of energy absorbed 0.8093 Joules and an average Impact Price of 0.0101 Joules $/ \mathrm{mm}^{2}$, this is due because the matrix binds well and enters the fiber pores. It also shows that as the volume fraction of the fiber is used, the absorbed energy value will be higher, because the matrix of the composite binds well to the fiber. This is also supported by Lokantara I.P. [7] which states that the impact strength increases with increasing volume and fiber fraction length.

\subsection{Macro Photo Analysis}
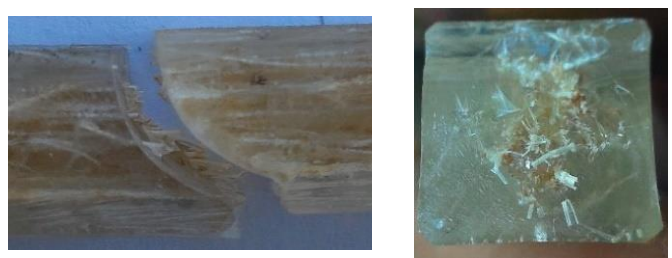

Figure 6 Macro photo results of impact testing of $10 \%$ fiber volume fraction
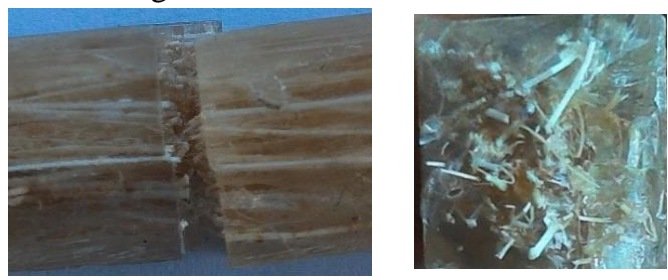

Figure 7 Macro photo results of impact testing of $20 \%$ fiber volume fraction
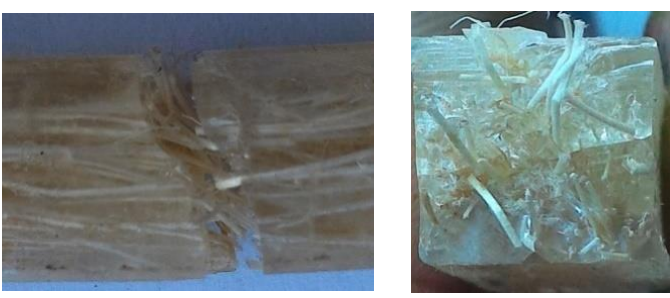

Figure 8 Macro photo results of impact testing of $30 \%$ fiber volume fraction
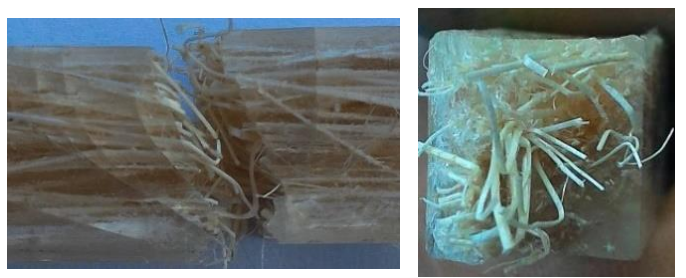

Figure 9 Macro photo results of impact testing of $40 \%$ fiber volume fraction
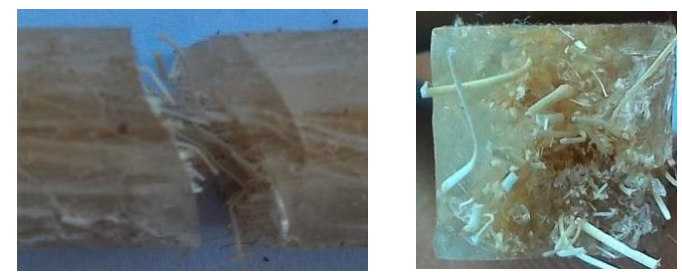

Figure 10 Macro photo results of impact testing of $50 \%$ fiber volume fraction
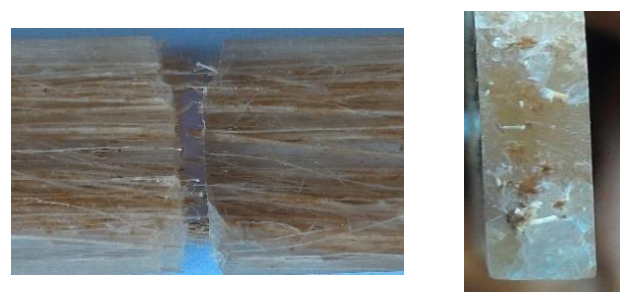

Figure 11 Macro photo results of tensile testing of $10 \%$ fiber volume fraction
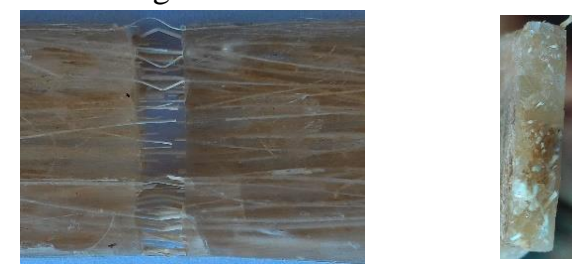

Figure 12 Macro photo results of tensile testing of $20 \%$ fiber volume fraction
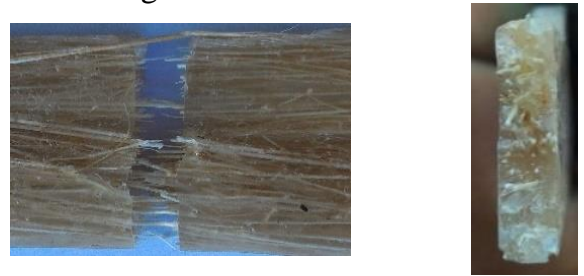

Figure 13 Macro photo results of tensile testing of $30 \%$ fiber volume fraction
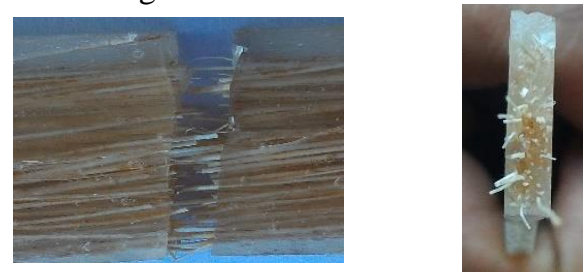

Figure 14 Macro photo results of tensile testing of $40 \%$ fiber volume fraction 

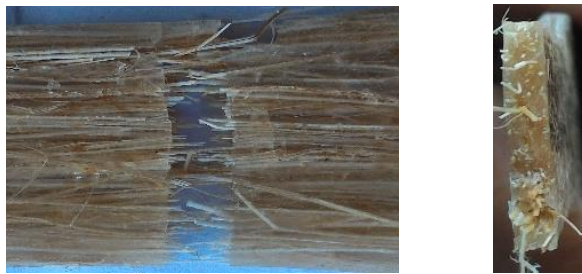

Figure 15 Macro photo results of tensile testing of $50 \%$ fiber volume fraction

\subsection{Discussion of Fracture Photos}

From the results of the fracture photos, it can be concluded that the fault that occurred was brittle fracture because it looked bright and crystallized. For the direction of crack propagation is perpendicular to the direction of the tensile stress at work. While the type of fault that occurs is the type of pull out fiber and broken fiber. Where pull out fiber is a condition where fiber comes out on a fault due to a less strong bond between the matrix and the fiber. While broken fiber is a fracture in the specimen where the fiber is broken or damaged and forms like fibers. Both of these faults are caused because there are voids around the fiber.

\section{Conclusions}

From the results of this research conducted on a composite matrix of banana stem fibers with a polyester matrix as a binder, it can be concluded that:

1. From the results of tensile testing, the most optimal tensile strength is found in the $10 \%$ fiber volume fraction and $90 \%$ matrix at $51.863 \mathrm{~N} / \mathrm{mm}^{2}$ and the strain value is $5.754 \%$. While the lowest average tensile strength value in the volume fraction of $20 \%-80 \%$ at $36,356 \mathrm{~N} / \mathrm{mm}^{2}$ with strain $7.796 \%$.

2. Based on the data graph above shows that the increasing percentage of fiber volume fraction affects the tensile strength and strain.

3. In the banana fiber the smallest impact energy absorbed is in the volume fraction of $20 \%$ $80 \%$ matrix with an average energy value of 0.4129 Joules and an average Impact Price of 0.0052 Joules $/ \mathrm{mm}^{2}$, while the absorption rate is the most optimal value than the other is the $50 \%$ volume fraction matrix $50 \%$ has an absorption rate with an average value of energy absorbed 0.8093 Joules and an average Impact Price of 0.0101 Joules $/ \mathrm{mm}^{2}$.

\section{References}

[1] Kroschwitz and Mehta P. (1987). Structure, Properties and Materials, New Jerse, Prentice Hall.

[2] Gibson, R, F. (1994). Principle of Composite Materials Mechanics, McGraw-Hill, New York

[3] ASTM. 1990. Standars and Literature References for Composite Materials, 2d ed. American Society for Testing and Materials. Philadelphia, PA.

[4] Schwartz, M.M., 1984, Composite Materials Hanbook, McGraw-Hill Book Co, New York.

[5] Rukmana, Rahmat. 2006. Usaha Tani Pisang. Kanisius, Yogyakarta.

[6] Teuku Rihayat and Suryani (2015). Pembuatan Polimen Komposit Ramah Lingkungan untuk Industri Otomotif dan Elektronik. Jurusan Kimia, Politeknik Negeri Lhokseumawe.

[7] Lokantara, L. P. (2012). Analisis Kekuatan Impact Komposit Polyester Serat Tapis Kelapa dengan Variasi Panjang dan Fraksi Volume Serat yang diberi Perlakuan NAOH, Fakultas Teknik Universitas Udayana Kampus Bukit, Jimbaran Bali. 